INDEPENDENT JOURNAL OF MANAGEMENT \& PRODUCTION (IJM\&P)

http://www.ijmp.jor.br

v. 11, n. 7, November - December 2020

ISSN: 2236-269X

DOI: 10.14807/ijmp.v11i7.1130

\title{
RESPONSIVENESS OF MILLENIAL (GENERATION Y) TO SOCIAL MEDIA RECRUITMENT CAMPAIGNS: EVIDENCE FROM PAKISTAN
}

\author{
Seema Chandani \\ Institute of Business Management, Pakistan \\ E-mail: snaushad.chandani@gmail.com \\ Adnan Bashir \\ Institute of Business Management, Pakistan \\ E-mail: adnan.bashir@iobm.edu.pk \\ Afaq Kazi Ahmed \\ Institute of Business Management, Pakistan \\ E-mail: afaq.kazi@iobm.edu.pk \\ Submission: 10/2/2019 \\ Revision: $12 / 3 / 2019$ \\ Accept: 2/12/2020
}

\section{ABSTRACT}

The utilization of social media has expanded rapidly in the 21st century; the majority of people use social media and social networking sites (SNSs) especially millennial “Generation Y” (born between 1980 to 1994 and now 26 to 40 years old). The purpose of the study is to observe the responsiveness of Millennial (Generation Y) to social media recruitment campaign in Pakistan. The research involves the dependent variable as recruitment and selection of generation $\mathrm{Y}$ and four independent variables as perceived costs, perceived risks, perceived opportunities, and perceived benefits. Survey sent to 150 respondents, out of which 106 being received. The data gathered was tested by using the SPSS for descriptive statistics, standard deviations, Correlation, regression analysis was done to check the relationship between dependent and independent variables. The results of the first objective revealed that the utilization of social networking in recruitment is inexpensive for many companies, the outcomes of the second variable indicated that when using social media, the human resource professionals gather consistent information for all candidates making fair and speedy hiring, to analyze the third objective, the outcomes have shown that there are numerous risks associated while using social networking sites and lastly when testing the fourth objective observed that various organizations don't have 
DOI: 10.14807/ijmp.v11i7.1130

job portal page for recruitment of Millennial (Generation Y) and majority candidates use LinkedIn, Facebook and Twitter for job searching. The study concluded that appropriate utilization of social networking sites in recruitment and selection of Millennial (Generation Y) provides excess to more extensive pool of candidates, is cost effective, faster and practical for organizations. They take benefit by utilizing social networking sites for recruitment campaigns yet the quality and competency of candidates not compromised however the candidate's information privacy risk need mitigation.

Keywords: Millennial (Generation Y), Perceived Cost, Perceived Benefits, Perceived Risks, Perceived Opportunities, Recruitment campaign, Social Media

\section{INTRODUCTION}

It has been identified that the utilization of social media has expanded rapidly globally (ARCHANA et al., 2014). In the $21^{\text {st }}$ century, the majority of people use social media. Every individual uses social networking sites (SNSs) such as Facebook, LinkedIn, and Twitter, etc. for sharing information and cultivate professional terms. These social networking sites have immensely developed through several countries and fascinated billions of individual users especially millennial (Generation Y) who were born between 1980 to 1994; they are currently between 26 to 40 years old. The usage of the internet has brought revolutionized in today's world of business.

Ellison (2007) explored that after the establishment of SNSs in 1997, several developments have been made and sites are not only used for sharing information, creating profiles, connecting and view the profile of each other but it is developed for several other purposes and business activities.

Kaplan and Haenlein (2010) define Social Media as "a group of internet-based applications that build on the ideological and technological foundations of web 2.0*, and that allow creation and exchange of user-generated content”. Conversely, there is no definition accepted globally of social media and many people assume that social network sites describe that what recognized social media is today and that the meaning of social networking sites will remain to modify and adapt from time to time (SCOTT; JACKA, 2011).

Internet with social media plays an essential role in the progress and vigorous competition as companies all over the globe utilizing abundant opportunities that social media is contributing maximum of their activities and operations of the organization. Social media is 
DOI: 10.14807/ijmp.v11i7.1130

certainly utilized in the organizational important function of human resources, particularly in recruitment and selection practices. SNS is utilized by companies to provide convenient service to invite and localize candidates and recruiters also facilitate to track prompt background checks.

On the other hand, peculiarly several companies escape utilizing the facility offered and take benefit from social media. Social media websites at firms level recognized to praise and enhance the effectiveness of different other traditional communication systems in the developed nations. Wolf et al., (2014) examined that social media engagement supports to reinforce the firm's brand loyalty and equity resulting in creating the organization more striking for the clients, present and prospective employees.

Social media tools have been widely executed to supplement the traditional inducting process in developed countries. There are many surveys conducted by the United States in 2008, a survey through US Society for Human Resource Management (SHRM) explored that since 2006 the number of organizations utilizing social media in the function of HRM has considerably developed. Furthermore, various companies to brand themselves are using social media channels to induct and contact candidates along with pre and post-interview selection.

Likewise, a current report from the UK by the commission for employment and Skills identified that several organizations in the country competently and professionally utilized social media as an element of recruitment and selection exercise (DAVISON; MARAIST; BING, 2011). A researcher examined that the risk elements such as security problems, cost of social media, internet access are the components that immensely influence the utilization of social media in financial firms (MURITTHI et al., 2014).

The above study proposes that the financial firms have become attentive and appreciate the challenges, opportunities and legal association of utilizing social media as an element of communication, it is not understandable from the past papers if they satisfy the above challenges, risks and opportunities, and legal issues about social media used as a recruitment tool.

Recent alteration in technology has tracked down new ways and chances for an organization to interact and execute social media which is commonly being restricted to marketing activities. Considering this, the goal of this research is to use this apparent gap to examine the utilization of social media in the recruitment of millennial (Generation Y). The 
DOI: 10.14807/ijmp.v11i7.1130

research aims to examine the use of social media in the recruitment of Millennial (Generation Y) in Pakistan. The research question of the studies are:

- What are the perceived costs related to the responsiveness of millennial (Generation Y) to social media recruitment campaign?

- What are the perceived benefits related to the responsiveness of millennial (Generation Y) to social media recruitment campaign?

- What are the perceived risks related to the responsiveness of millennial (Generation Y) to social media recruitment campaign?

- What are the perceived opportunities related to the responsiveness of millennial (Generation Y) to social media recruitment campaign?

\section{Literature Review}

The growth of the digitalized world has transformed in both ways of people's interaction, particularly private and extremely with each individual and with the company in terms of the working environment. Several researches indicate that employers are enforcing to grasp the advanced technology to make themselves upgrade in recruitment activities. According to Smith and Rupp (2004) as they claim that: “The Internet has drastically changed the face of recruitment. Employers must now actively market themselves by instituting a wellimplemented e-recruitment program to find better quality candidates and improve hiring decisions, all in less time and at a lower cost”.

In this fast-growing world, the internet is used by majority employers in e-recruitment services which tend to provide benefit to the traditional recruitment practices. E-recruitment has immense advantages as the relatively old process of hiring. It permits the organization to fasten the recruitment process and save time in hiring through fast-tracking information flow in a short period. It also supports decrease hiring costs and times since all practices are automated screening, interviews, and statistical forecasts.

Smith and Rupp (2004) explain that Moving recruitment process from the paper and time-escalated manual technique to a computerized one saves time and cash and improve efficiency by leaving positions empty for shorter timeframes. Likewise, the expense related to posting on a job board contrasts well and putting work advertisements in papers, and, now and again, might be more cost-effective or inexpensive. 
DOI: 10.14807/ijmp.v11i7.1130

There are few disadvantages for job seekers as they search online jobs and share their $\mathrm{CV}$ online but there is a problem of risk and security as personal information can be misused. This research review the literature related to what and why cost, benefits, risks, and opportunities are related to the use of social media in the recruitment of Millennial (Generation Y) of different sectors.

\subsection{The cost associated with the use of social media in the recruitment process.}

Armstrong (2010) indicated that Human Resource Management (HRM) is authorized in controlling all features regarding managing employees in companies. Conversely, a researcher adds that employees are like different resources in the firm and required to oversee them adequately to ensure the best execution for the whole organization (COMPTON, 2009). De Alwis, (2010) investigated that employees are an important resource that enables the improvement and advancement of organizations and consequently they should be looked after well. The electronic recruitment and selection came about into cost sparing and expanded talent acquisition advertisement out of the geographical limits, and also optimizing the way toward reaching candidates and making a good reputation for the company (CAPPELLI, 2001).

According to Wolf et al., (2014) online networking sites have been recognized to praise and enhance the productivity of other customary linkages of correspondence in developed nations in the West. Participating in online networking likewise reinforces the company's image value and accordingly making the organization more attractive to the clients, and present and potential staff of the company.

Online networking has facilitated to enhance proficiency in human resource management where the advantages, for instance, expanded employee commitment (RAI, 2012), improving employee superiority (FREER, 2011) and fortifying employees feeling of social relations has been seen. Also (EDOSOMWAN et al., 2011) examined that eventually social media assists in making a company's good standing and through online networking, the firm can over and again strengthen brand image.

As Ndambiri (2017) examined that several organizations in the United States have effectively incorporated web-based social networking inside their functional departments, research shows that many organizations have experienced challenges in such a manner. The researcher examined that various companies were not comfortable with the innovations but rather most just essentially neglected to distribute the resources expected to incorporate social networking through organization functions. Milano et al., (2011) explored that deprived 
DOI: 10.14807/ijmp.v11i7.1130

technical proficiency and decision making delayed by management added to the deficiency and poor utilization of social networking.

Brown and Vaughn, (2011) investigated that as per past practice, wherever organization recruits employees, they would need to advertise the new job openings in a local newspaper, recruit outsource agency or post the vacant position on the social networking sites. This traditional approach is gradually reaching an end. It was accounted for that Monster.com a career site created by UK and U.S in 2009 that encounters a 31\% decrease in income. This was particularly to decrease in the recruitment business as this was experienced universally. HR specialists and recruitment consultants have been compelled to adopt a proactive strategy by making talents busy through the utilization of social media sites.

\subsection{Benefits associated with the use of social media in the recruitment process.}

There are many different social media tools such as LinkedIn, Twitter and Facebook play a vital role in the overall process of recruitment and selection that gives information on recruitment, developing and promoting specific job opportunities amongst recruiters. Similarly, the research described that social sites were not only important for attracting future employees, however, it also a component that could suggest the opportunities for an actual job to candidates. Therefore, potential candidates can get information about recruiters through social media sites and company web pages (SEARLE, 2006).

The majority of the firms don't make any plans and strategies for using social networking for recruitment and acquisition purposes. A research study by SHRM (2008) the total $72 \%$ of companies did not follow any official or unofficial strategies when it comes to hiring through online web sites for recruitment and selection process, also 89\% of companies are unsuccessful and unaware to execute any strategy and plans. Furthermore, a researcher proposed that companies must follow the strategies and policies that have to be utilized for discourse the risks associated with electronic hiring (DAVISON, 2012).

There is a great range for 'traditional' approaches in which organizations utilize to attaining at the expectation of strong employee, additionally, a tremendous amount of literature, particularly on Human Resource from teachers and professionals on how to explore for the new competent candidate, would frequently prepare quickly and upgraded. The previous practice of hiring mostly include paper advertisements, paper application, resume, and CVs, or face to face interaction and telephone calls. 
DOI: 10.14807/ijmp.v11i7.1130

A study explained that these channels to those greatest part trust the questionable 'spray and pray' technique where the immense numbers of applications and ads are sent out ('sprayed') while every company and job hunters wait ('pray') for the response. With that development of the online web and networking a considerable measure explicitly, new methodologies have begun in the domain of employment and recruiting (JOOS, 2008).

\subsection{Risks associated with the use of social media in the recruitment process.}

In the opinion of (CLARK; ROBERTS, 2010) that online networking offers several advantages for the organization in respect of developing economies and focusing recruitment, use of Social networking in recruitment purpose brings explicit risks and costs. The most genuine legal risks and commonly some greater part about more extensive ethical queries relate to identifying with the problem of screening.

The preparation of utilizing online networking sites for pre-hiring screening and selection has developed to be very famous. Even though not seen as strange in this advanced era, utilizing social media has verified to be a guaranteeing basis for candidate's information, nevertheless, it is also encountered with potential risks that have both legal and ethical outcomes. This obtains about incompatible opinions for utilizing social networking in hiring between employers and employees, also legal frameworks.

This practice of hiring using social networking sites is relatively innovative, its consequences are untested legally. However, provided the broad range of selection of knowledge employers can have the ability to access online any time freely as well as longevity and stability, there is distinctly a range of ground on which applicants might encounter the practice as demonstrated by (BROWN; VAUGHN, 2011). If applicants are tuned down on the indication of erroneous data, notably if received without their consent, management might aspect legal challenges (DAVISON, 2012). An additional issue can likely defamation of character through on-line posts with third parties: "defamation of character can be a tangle if websites contain inaccurate and slanderous data that may be a major legal concern with traditional background checks” (DAVISON, 2012).

According to Brown and Vaughn (2011) explained that employers are more exposed to the utilization of on-line screening, this might ultimately bring the result of legal activities. The case for companies functioning in numerous settings are likewise sophisticated, also as ensured classes and discrimination laws and rules can change country to country (DAVISON, 2012). 
DOI: 10.14807/ijmp.v11i7.1130

If management in some later intention needed to release those workers looking into ability and competence grounds, the worker might potentially claim discrimination, reinforced by the fact that the leader was alert of their political or spiritual beliefs. Though they are verified on a legal basis, management must with the consideration those justifications for the workrelated of any information found through internet online screening.

Additionally Brown and Vaughn, (2011) identified that the requirement for "welldocumented proof for validity" to duplicate data utilized in recruitment. Furthermore, an element of fine and satisfactory recruitment practice potentially violated by the employment of online screening is that the obligation to the extent that potential companies gather consistent information for all applicants.

Positive talent and abilities that can be highlighted in the applicant's profiles consist of creativity, vast knowledge, good correspondence skills and strong references from others. However, generally shown pleasing side of the candidate's online profile was certainly least tangible, $50 \%$ of employers were considered to hire whether they got decent concern to those applicant's personalities from their profile.

There are possible risks here, related to possible breaches of privacy, also the validity and reliability of the findings gathered. The majority of the people may not have thought that the online profiles are being seen and should have an objection to that. Moreover, employers could be certain that the text of the online profiles is accurate as people may prepare profiles specifically for the potential companies to express at (DAVISON et al., 2011).

\subsection{Opportunities associated with the use of social media in the recruitment process.}

Davison et al., (2011) explained that a generally large number of surveys on online networking recruitment and decision have been done inside the United States, the place where the usage on online networking sites may be turning under broad in recruitment. For example, in 2008, investigation in the united states the Society for Human Resource Management (SHRM) discovered that the number of companies that shown utilizing social networking sites as an HR device climbed to $41 \%$ in 2008 from $21 \%$ in 2006. The percentage of those who were utilizing these sites as a promoting device for induction and interact with applicants is $34 \%$ and $13 \%$ were utilizing them as a screening device. 
DOI: 10.14807/ijmp.v11i7.1130

A current international research amongst companies that emphasizes the growth in importance of online networking in staffing and additionally its future possibilities: "92 percent for participants utilize or are determined to utilize social networking media for recruiting, growth of just ten percent from the eighty-three percent generally utilizing social recruiting in 2010” (NDAMBIRI, 2017).

Furthermore, since 1998, there has been a 60\% rise in applications through social websites, with above $90 \%$ globally 500 companies using this characteristic will attract potential employees (SEARLE, 2006). Similarly, a study conducted by Ndambiri, (2017), in the form of staffing in the United States. It categorically might have been analyzed that thirty-three percent of participants stated that the duration to induct employees got upgraded, besides forty-three percent asserted that the number of applicants has incredibly enhanced.

Organizations are starting to promote and post new job openings on the web to identify the rising and more diverse traffic on the networking website. Cappelli, (2001) identified that $75 \%$ of fortune 500 organizations are placing vacancies on their company's websites, and after few months ninety percent of big US firms are utilizing social media for recruitment and selection. Furthermore, above seventy-five percent of human resource experts are currently utilizing traditional staffing systems for recruiting as a supplement. It is obvious that web-based recruiting and job searching are now a big trend, as this is the developing tool for the utilization of the web for business purposes.

\subsubsection{Facebook/LinkedIn}

The most recent facts show that there are more than 20 million experts on LinkedIn all over Europe and there have been more than 85 million network members around the world. One Million to Five million users overall signed up LinkedIn in the UK between June and December 2010. 3 site demographics disclosed that Thirty-Eight percent of employers generate income more than $£ 50,000$ annually and Thirty-one percent income between $£ 30,000$ and $£ 50,000$ was generated yearly. Twenty-Five percent of FTSE 100 organizations induct through LinkedIn and about 700,000 LinkedIn interaction clusters. Media, Information technology and finance are the primary industries of recruiting through LinkedIn. Just between ten to twenty percent, people are vigorously searching for a job on LinkedIn (BOLOTAEVA; CATA, 2010).

Despite organizations are attracting and fetching with Facebook for recruiting purposes, they do it expressively less than the alternate familiar social media networks. The actuality is that Facebook could influence more individuals to utilize the webpage professionally and 
DOI: 10.14807/ijmp.v11i7.1130

proficiently, it might begin with contending with sites, for example, LinkedIn for professional demographic. Although Facebook has above four hundred million members more than LinkedIn, current detail based on age demonstrates that LinkedIn and Facebook have almost an equal number of professional users.

In the last one year, the webpage started with an advance under a place in which to conduct business also create expert associations. Extensive organizations, comprising large portions of customer brands, utilizing 'fan pages' for marketing the service and products to customers, and also should drive movement of the job search pages on conventional sites. The new 'resume' style profile additionally permits prospective applicants to stimulate their aptitudes, abilities, knowledge, and experience inside these forums (SUBHANI et al., 2012).

\subsubsection{Twitter}

Archana et al., (2014) identified that the utilization of social media has expanded speedily globally. Social Media Sites, for example, Twitter, Facebook, LinkedIn, and Google is examples of networking sites utilization to induct and appoint employees. Thirty-six to fifty percent of clients belong to college graduates who are searching for work opportunities. Companies utilize Twitter to post job advertisements.

A survey conducted via Career Xroads in the United States examined that forty-two percent of fortune 500 organizations use twitter, Facebook or LinkedIn for the hiring of the candidates. In 2010, eighty-three percent of employers utilized social networking sites and in 2011, eighty-nine percent utilized web-based sites as a basis of employment. Forty-nine percent of recruiters were intending to utilize twitter for hiring and selection, eighty-seven percent LinkedIn and fifty-five percent face book. Job searchers and hunters are getting the benefit of twitter to assist them to search for job opportunities.

\subsection{Conceptual framework}

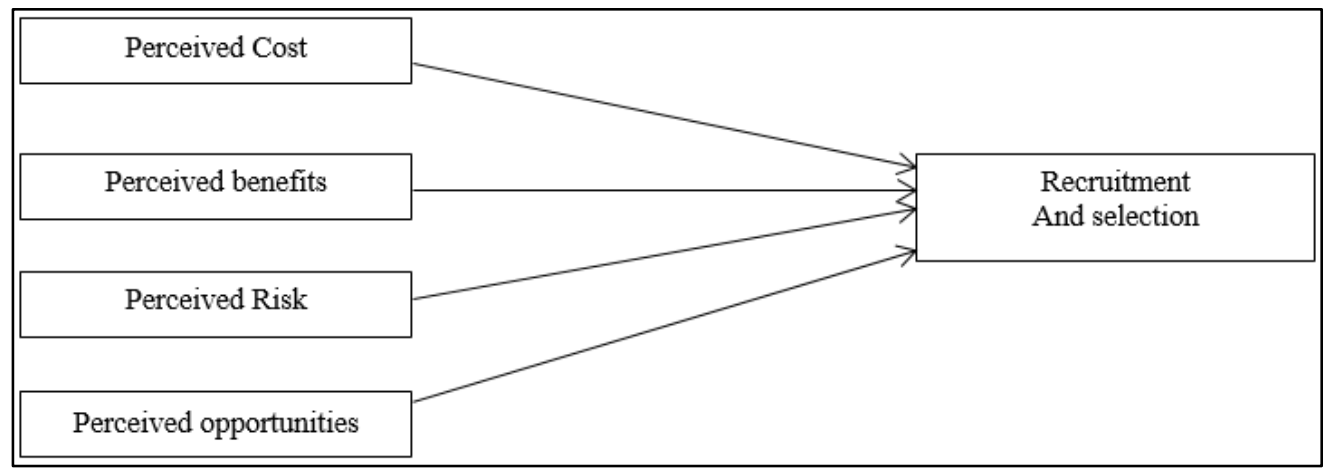

Figure 1: Conceptual Framework

Source: Ndambiri (2017) 
DOI: 10.14807/ijmp.v11i7.1130

\subsection{Hypothesis}

- H1: The relationship between the perceived cost of social media and effective recruitment campaigns for Millennial (Generation Y) is significant.

- H2: An association between the perceived benefits of social media and effective recruitment campaigns for Millennial (Generation Y) is significant.

- H3: An association between perceived risk of social media and effective recruitment campaigns for Millennial (Generation Y) is significant.

- H4: An association between perceived opportunities of social media and effective recruitment campaigns for Millennial (Generation Y) is significant.

A survey questionnaire was developed to conduct this study. The data gathered was tested by using the SPSS for descriptive statistics, standard deviations, Correlation, regression analysis was done to check the relationship between dependent and independent variables. Recruitment and selection of Millennial (Generation Y) were used as a dependent variable, whereas perceived cost, perceived benefits, perceived risks, and perceived opportunities were taken as an independent variable as they are associated with the use of social media in recruitment and selection of Generation Y. (BRYMAN, 2006) explained that the research design is the method of opting for the process through which the correct evidence will be gathered.

\subsection{Sample size and data collection}

The research targeted human resource professionals from different companies and hence a survey was utilized. Non-probability convenience sampling is being used for this study. A survey took a substantial number of respondents and hence created a high degree of statistical confidence. The researcher sent a questionnaire to 150 participants through email and by hand, out of which 106 filled and sent back, hence the response rate is $71 \%$, and the rest of $29 \%$ were not willing to fill the questionnaire.

We used primary data for this study. The most frequently used data collection tool is the survey questionnaire (BOWLING, 2005). A questionnaire is a data collection tool considered to gather both structured and sometimes unique data from the participants (SANSONI, 2011) 
DOI: 10.14807/ijmp.v11i7.1130

The survey questionnaires used in this research had closed-ended questions. The questions addressed the objectives of the study which is to investigate what is perceived costs, perceived benefits, perceived risks and perceived opportunities associated with social media use in recruitment and selection of Millennial (Generation Y) in the different organizations of Pakistan. The five-point Likert scale was used in this study. The questionnaire is adopted from the study of (NDAMBIRI, 2017) consists of 45 questions (Appendix I) and sent to the participants through online Google forms and by hand.

\subsection{Variables Description}

The Statistical Package for Social Sciences (SPSS) was used to analyze the data.

The assumption of the linear regression equation was:

$\mathrm{RS}=\beta 0+\beta 1 \mathrm{PCT}+\beta 2 \mathrm{PBT}+\beta 3 \mathrm{PRT}+\beta 4 \mathrm{POT}+\mathrm{e}$

Where: RS= Recruitment and selection:

$\beta 1, \beta 2, \beta 3$, and $\beta 4$ are constants

PCT $=$ Total Perceived cost of social media

PBT $=$ Total Perceived Benefits of social media

PRT $=$ Total Perceived Risks of social media

POT $=$ Total Perceived opportunities of social media

$\mathrm{e}=$ Error Term

The respondents have been enquired a set of questions to check that at what extent they agree or disagreed with statements related to all variables utilizing a five-point Likert scale where 1 - Strongly Disagree 2 - Disagree 3 - Neutral 4 - Agree 5 - Strongly Agree

The data was subjected to a reliability test where Cronbach's Alpha was used to check whether the data met the threshold. Validity was tested by the use of factor analysis to determine whether the construct under investigation meets the required threshold of 0.4. A Pearson correlation was employed to test the relationship between the dependent and independent variables, therefore, establishing whether there existed a positive or a negative relationship. A regression analysis was undertaken to estimate the strength and direction of the relationship between the dependent and independent variables. 
ISSN: 2236-269X

DOI: 10.14807/ijmp.v11i7.1130

\section{ANALYSIS}

Inferential statistics are utilized to explain the association amongst dependent and independent variable, in this regard for this research paper, correlation and regression analysis was conducted.

Table 1 represents the summary of the descriptive statistics of this research. Social media in recruitment and selection is not costly to contact an extensive pool of candidates, organizations have reduced recruitment and selection time via social media (4.02). The participants proved that applicants received greater information through social media as it offers applicants easy and speedy posting job vacancies and it also shows that the companies use particular online recruitment websites to create interest for Millennial (Generation Y)and also that social networking plays a vital part in recruitment and selection as a lot of people are getting more benefits (4.03).

There are several risks associated while using social networking sites and there was an uncertainty on other attributes such as political associations or physical presence are unrelated in online networking recruitment and selection, Human Resource Managers have examined during screening, that the information which has instigated them not to induct an applicant, hence while using social media candidates resumes and private information are readily accessible via HR consultants or third party (3.80).

Most of the respondents agree that social media plays an essential role in the recruitment of Millennial (Generation Y)in majority of the organizations and Human Resource Managers have access to an extensive pool of competent candidates from online networking, people are getting more job opportunities from both social networking sites LinkedIn and Facebook as these sites are widely used (4.10). Companies clearly defined the job objectives, requirements and applicant specification in the recruitment and selection process, it was also discovered that online networking sites provide competent applicants and do timely recruitment and selection (3.90).

Table 1: Descriptive Statistics

\begin{tabular}{lrrrrrrr}
\hline & $\mathbf{N}$ & Mean & Std. Deviation & \multicolumn{2}{c}{ Skewness } & \multicolumn{2}{c}{ Kurtosis } \\
& Statistic & Statistic & Statistic & Statistic & Std. Error & Statistic & Std. Error \\
\hline PCT & 106 & 4.0217 & .58684 & -.042 & .235 & -1.261 & .465 \\
PBT & 106 & 4.0321 & .48845 & -.255 & .235 & -1.108 & .465 \\
PRT & 106 & 3.8057 & .51118 & -.139 & .235 & -1.157 & .465 \\
POT & 106 & 4.1000 & .36174 & -.748 & .235 & .845 & .465 \\
RST & 106 & 3.9038 & .57187 & .194 & .235 & -.907 & .465 \\
Valid N (listwise) & 106 & & & & & & \\
\hline
\end{tabular}


DOI: 10.14807/ijmp.v11i7.1130

Table 2 demonstrates the reliability analysis, the findings show that all variables met the threshold, hence these could be utilized for further analysis. If Cronbach Alpha value is 0.6 that is measured as poor, the value 0.7 is acceptable and the value 0.8 is characterized as good (BONETT; WRIGHT, 2015). The findings are illustrated in table 4.2 below:

Table 2: Reliability Statistics

\begin{tabular}{lcc}
\hline Variables & No. of Item & Cronbach's Alpha \\
\hline PCT & 10 & 0.882 \\
PBT & 10 & 0.799 \\
PRT & 10 & 0.855 \\
POT & 10 & 0.785 \\
RST & 5 & 0.765 \\
& & \\
\hline
\end{tabular}

A Pearson correlation investigation was conducted to find the association between the recruitment and selection with independent variables such perceived cost, perceived benefits, perceived risks and perceived opportunities the finding revealed a strong positive association amongst all variables and all have a significant relationship as illustrated in Table 3 below:

Table 3: Correlation Analysis of Social Media Use against Co-Factors

\begin{tabular}{llrrrrr}
\hline & & PCT & PBT & PRT & POT & RST \\
\hline PCT & Pearson Correlation & 1 & & & & \\
& Sig. (2-tailed) & & & & & \\
PBT & Pearson Correlation & $.763^{* *}$ & 1 & & & \\
& Sig. (2-tailed) & .000 & & & & \\
PRT & Pearson Correlation & $.739^{* *}$ & $.752^{* *}$ & 1 & & \\
& Sig. (2-tailed) & .000 & .000 & & & \\
POT & Pearson Correlation & $.669^{* *}$ & $.721^{* *}$ & $.652^{* *}$ & 1 & \\
& Sig. (2-tailed) & .000 & .000 & .000 & & \\
RST & Pearson Correlation & $.300^{* *}$ & $.337^{* *}$ & $.192^{*}$ & $.403^{* *}$ & 1 \\
& Sig. (2-tailed) & .002 & .000 & .004 & .000 & \\
\hline
\end{tabular}

**. Correlation is significant at the 0.01 level (2-tailed).

*. Correlation is significant at the 0.05 level (2-tailed).

The study analyzed the association amongst the dependent variable (use of social media on recruitment and selection) against other core factors. The findings demonstrate that the Adjusted R2 value is .163 hence $16.3 \%$ variation of the use of social media in recruitment and selection is described by the variation in Perceived Cost, perceived benefits, perceived risk, and perceived opportunities, hence $83.7 \%$ is described by other variables not taken in this study as illustrated in table 4:

Table 4: Model of Goodness of Fit

\begin{tabular}{lrrrrr}
\hline Model & R & R Square & Adjusted R Square & Std. Error of the Estimate & Durbin-Watson \\
\hline 1 & $.441^{\mathrm{a}}$ & .194 & .163 & .52333 & 2.455 \\
\hline a. Predictors: (Constant), POT, PRT, PCT, PBT & & \\
b. Dependent Variable: RST
\end{tabular}


DOI: 10.14807/ijmp.v11i7.1130

An ANOVA analysis is conducted on all dependent variables of Social media (Perceived Cost, Perceived Benefits, Perceived Risk and Perceived Opportunities) and independent variable (Recruitment and Selection at 95\% confidence interval as F critical value is 6.096 and the p-value is 0.000 , therefore the overall model is significant as illustrated in table 5 below:

Table 5: ANOVA

\begin{tabular}{|c|c|c|c|c|c|}
\hline Model & Sum of Squares & Df & Mean Square & $\mathbf{F}$ & Sig. \\
\hline 1 Regression & 6.678 & 4 & 1.669 & 6.096 & $.000^{\mathrm{b}}$ \\
\hline Residual & 27.661 & 101 & .274 & & \\
\hline Total & 34.338 & 105 & & & \\
\hline
\end{tabular}

Table 6: Coefficients

\begin{tabular}{|c|c|c|c|c|c|c|}
\hline \multirow{2}{*}{\multicolumn{2}{|c|}{ Model }} & \multicolumn{2}{|c|}{ Unstandardized Coefficients } & \multicolumn{3}{|l|}{ Standardized Coefficients } \\
\hline & & B & Std. Error & Beta & $\mathbf{t}$ & Sig. \\
\hline \multirow[t]{5}{*}{1} & (Constant) & 1.334 & .585 & & 2.280 & .025 \\
\hline & PCT & 104 & 149 & .107 & 698 & .487 \\
\hline & PBT & .230 & 192 & .196 & 1.199 & .233 \\
\hline & PRT & .308 & .167 & -.275 & -1.850 & .067 \\
\hline & POT & .585 & .214 & .370 & 2.736 & .007 \\
\hline
\end{tabular}

a. Dependent Variable: RST

According to table 4.6 , the equation the equation $(\mathrm{RS}=\beta 0+\beta 1 \mathrm{PC}+\beta 2 \mathrm{~PB}+\beta 3 \mathrm{PR}+$ $\beta 4 \mathrm{PO})$ becomes:

$\mathrm{Y}=$ alpha $+\beta(\mathrm{X})$

$\mathrm{RST}=1.334+0.104(\mathrm{PCT})+0.230(\mathrm{PBT})+0.308(\mathrm{PRT})+0.585(\mathrm{POT})+\mathrm{e}$

Where RST is the dependent variable as the use of media in recruitment and selection total

PCT: perceived costs total

PBT: perceived benefits total

PRT: perceived risks total

POT: perceived opportunities total

Table 6 demonstrated the regression equation that has established considering all factors (perceived benefits, perceived opportunities, perceived opportunities, and perceived costs) and all factor are constant, recruitment and selection was 1.334. The result shows that with all other variables held at zero, a unit change in the cost would result in a 0.104 increase in recruitment and selection, similarly, a unit change in benefits also directed to 0.230 variations in 
DOI: 10.14807/ijmp.v11i7.1130

recruitment and selection. Furthermore, the research revealed that the variation in perceived risks would lead to a 0.308 change in recruitment and selection. Moreover, a unit variation in perceived opportunity would direct to 0.585 change in recruitment and selection.

The four variables checked in this study presented that risks and opportunities had a positive significant association with recruitment and selection, hence perceived benefits and costs had a positive insignificant association with the dependent variable. It is therefore concluded that two described the disparity in recruitment and selection.

\section{DISCUSSION}

The findings of tested hypotheses revealed that there is a positive impact of independent variable Perceived cost, perceived benefits, perceived risks and perceived opportunities on dependent variable recruitment and selection. Secondly, the study also revealed a strong positive association amongst all variables and all have a significant relationship.

\section{H1: The relationship between the perceived cost of social media and effective recruitment campaigns for Millennial (Generation $\mathrm{Y}$ ) is significant.}

The study aimed to determine if the perceived cost influence on recruitment and selection. The hypothesis was developed based on previous literature and studies. Nowadays many human resource professionals of any organization using advanced technological base websites for recruiting candidates like these are less costly or inexpensive than the traditional approaches of hiring employees such as newspaper advertisement.

Clements (2012) discovered that it is less expensive to access to a more extensive pool of applicants utilizing web-based social networking, and many companies have planned equal opportunity and diversity approaches. A Researcher states Jon Hull, global Head of Resourcing at RS segments, that generally, recruiting for a senior post using online networking costs them $£ 714$, compared with $£ 7,500$ through the ancient methodologies such as a paper advertisement (CLEMENTS, 2012). Similarly, (BROWN; VAUGHN, 2011) also explained that social media may be utilized as a part of equivalent open door, social activity and diversity approaches of companies, as it most likely allows recruiters to take advantage of online talks and discussions and opportunities and effectively occupy applicants in cluster, therefore they could somehow or another not influence through more conventional recruitment channels like newspaper.

The outcomes of this research validate the association between perceived cost and recruitment and selection. It has also been found that there is a positive significant association amongst perceived cost and recruitment and selection. According to the hypothesis we tested, 
DOI: 10.14807/ijmp.v11i7.1130

there's a strong positive relationship between perceived cost and recruitment and selection which is statistically significant. Perceived cost plays an active role in social media for the organization and recruiters as they spend less amount in recruitment and selection of the employees.

Hence, considering the secondary literature and analyzing the outcomes of this study, it can be recommended that social networking sites if used by taking into account job seeker's needs and desires while posting the jobs by technological experts drastically improve employee selection.

\section{H2: An association between the perceived benefits of social media and effective recruitment campaigns for Millennial (Generation Y) is significant.}

The study aimed to determine if the perceived benefits influence on recruitment and selection. The hypothesis was developed based on previous literature and studies. To examine the second goal, the outcomes have shown that when utilizing social networking sites, the Human Resource professional gather systematic and consistent data for all candidates making hiring fair for all. Communicating tools such as Facebook, LinkedIn, and Twitter assume a significant practice within the general procedure around hiring, giving recruitment information and promoting realistic employment desires among potential recruiters.

Searle (2006) identified that not exclusively is the significance of social networking sites in attracting forthcoming employees however, it likewise a reality that they may help to extend to practical employment opportunities to applicants. Consequently, a potential applicant can pick up a lot of information about the potential organization through its social networking pages. Joos, (2008) explains new strategies for recruiting haven't yet considered very much of traditional methodologies though rather supplemented current human resource methods "Social media tools and techniques as presently used don't seem to be an instantaneous replacement for ancient hiring processes, however rather a supplement to them".

Similarly, a researcher noticed that few people have claimed that these web search conveniences give distinct methods to use for hiring, nevertheless once looked at in extra detail, it may look like old job searching is as yet being managed through this new channel (SEARLE, 2006). A researcher proposed that companies should implement some guidelines that might be utilized to identify risk associated with social media hiring (DAVISON, 2012). Most companies don't have guidelines that follow best selection practices (DAVISON et al., 2011). 
DOI: 10.14807/ijmp.v11i7.1130

The results of this research validate the association between perceived benefit and recruitment and selection. It has also been found that there is a positive significant association amongst perceived benefit and recruitment and selection. According to the hypothesis we tested, there's a strong positive relationship between perceived benefit and recruitment and selection which is statistically significant. Perceived benefit plays a vital role in social media for utilizing social networking sites as the Human Resource manager gathers systematic and consistent data for all candidates making hiring fair and equitable for all candidates.

Hence, considering the secondary literature and analyzing the outcomes of this study, it can be recommended that social networking sites if used by taking into account job seekers benefits by making recruitment fair and equitable for all applicants.

\section{H3: An association between perceived risks of social media and effective recruitment campaigns for Millennial (Generation Y) is significant.}

The study aimed to determine if the perceived risks influence on recruitment and selection. The hypothesis was developed based on previous literature and studies. To examine the third objective, the result shows that when the Human Resource Managers while using social networking sites to gather systematic information for all candidates for making hiring with rational, equal and fair to all, whoever use social media for job seeking purpose should be careful about giving the right information to the employer, and also employer should be very much vigilant while sending the resume of candidate to the third party for the employment purpose, but before sending employer should take permission from candidate as it comes under ethical outcomes.

Clark and Roberts (2010) indicated that social media proposes clear advantages to the organizations regarding making economies and focusing on recruitment, use of web-based social networking to hire conjointly conveys specific costs and risks. The most genuine legitimate risks and also a dominant part of more extensive ethical questions tend to identify with the issue of screening, as the practice of utilizing social communication sites for pre-work screening and recruiting has become extremely well-known.

Even though not seen as unusual in this tech-savvy era, utilizing social networking has turned out to be an optimistic source for candidate's information, yet it is also aspect challenge with prospective risks, that have both lawful and ethical outcomes. This achieves clashing perspectives about utilizing online networking in hiring among company and company representatives and also legal frameworks. 
Furthermore, Davison (2012) explained that if applicants are turned down on the possibility of wrong information, particularly, if they got without their permission, the company could confront the legal problem. Additionally Brown and Vaughn, (2011) explored that the requirement for "well-documented proof for validity" to duplicate data used in hiring purposes.

Furthermore, satisfactory recruitment practice potentially violated by the employment of online screening is that the obligation to the extent that potential companies gather consistent information for all applicants. According to Davison, (2012) majority respondents agreed that the recruiter informs candidates before viewing their profiles. Getting information about the candidate through social networking sites is also classified as an invasion of a candidate's privacy, particularly if administered without their approval or consent.

The results of this study validate the relationship between perceived risks and recruitment and selection. It has also been found that there is a positive significant association amongst perceived risks and recruitment and selection. According to the hypothesis we tested, there's a strong positive relationship between perceived cost and recruitment and selection which is statistically significant.

Perceived risk plays a vital role in social media for utilizing social networking sites as the Human Resource manager gathers systematic and consistent data for all candidates making hiring fair and equitable for all candidates. Candidates should be vigilant while using social networking portal for sending resume for job purpose, so they provide accurate information as it is used for further screening and employer should be very careful while obtaining information of candidates and keep it in safe and as this document is the candidates privacy and if recruiter wants to send to the third party so first take the consent of that particular candidate which is ethically correct.

\section{H4: An association between perceived opportunities of social media and effective recruitment campaigns for Millennial (Generation $\mathrm{Y}$ ) is significant.}

The study aimed to determine if the perceived risks influence on recruitment and selection. The hypothesis was developed based on previous literature and studies. Examination of the fourth objective shown that different organization is bound to utilize social networking sites for hiring and induction of Generation Y. In the western world, several surveys on webbased networking sites hiring have been done within the United States, where the usage of 
DOI: 10.14807/ijmp.v11i7.1130

social networking sites is transforming into a well-known recruitment application. In 2008, for example, a study for the United States Society for Human Resource Management (SHRM) found that many companies that demonstrated utilizing social networking sites as a human resource application had ascended from 21 percent in 2006 to 44 percent in 2008.

By 2010, it's approximated that above fifty percent of UK job hunters were utilizing one or various web-based social networking sites as a role of their job search (WRIGHT, 2011). Bosworth, Kik and Constable, (2012) reported that in the UK, companies effectively utilization of social networking sites as a medium for hire. Numerous Companies in Europe utilize Facebook and LinkedIn as a source for inducting staff. They utilize job portals on their Facebook page, thus creating recruitment more viable and productive.

Furthermore, DeKay (2009) noticed that most of the companies are shifting to online networking as a source of recruitment and selection. According to the European report, about $100 \%$ of young job hunters under the age of twenty-five would like to correspond online with recruiters. In Germany, the top 1,000 companies are Facebook users and utilize them for staffing. Likewise, companies use Twitter as a hiring source. They post vacant positions on their twitter account, hunting for the competent candidate through Twitter, and inquire applicants for proficiencies and abilities (HUNT, 2010).

The researchers observe that the majority of companies don't have a job portal page focusing on Generation Y. On the other hand, companies utilize LinkedIn to post new job opportunities. Job hunters are given an equivalent chance to go searching for development and career advancement, members are prepared to trace different companies and obtain information for available job positions, and do inquire about in regards to the corporate. Furthermore, LinkedIn has built up a site where questions might be asked and responded to (SUBHANI et al., 2012).

Similarly, this opposes a current universal research between companies underlines the escalation insignificance of online networking in hiring and also its prospect: "92 percent of respondents use or are determined to use social media for recruiting, a rise of just about ten percent from the eighty-three percent already using social recruiting in 2010" (NDAMBIRI, 2017).

Also, since 1998, there has been a $60 \%$ rise in job applications via online sites, with more than $90 \%$ globally 500 companies using this element to attract the potential candidate. There are many professional online sites keeping candidates informed of future opportunities 
DOI: 10.14807/ijmp.v11i7.1130

across an extensive scope of firms. Geographically inadequate applicants can access prospect job opportunities easily" (SEARLE, 2006).

According to the hypothesis we tested, there's a strong positive relationship between perceived opportunities and recruitment and selection which is statistically significant. Perceived opportunities play a vital role in social media for utilizing social networking sites as the Human Resource manager gathers systematic and consistent data for all candidates making hiring fair and equitable for all candidates. Social networking sites such as Facebook pages, Twitter, and LinkedIn and job portals are useful for both job seekers and organizations as they both get to benefit from these networking sites.

\section{CONCLUSION}

Based on the data analysis and research outcomes, it was concluded that Social media sites have a positive and significant impact on the recruitment and selection process. Similarly, perceived cost, perceived benefits, perceived risks, and perceived opportunities have a strong relationship with the recruitment and selection process of millennial (Generation Y).

The research concludes that the proper utilization of online networking in recruitment and selection is reasonable for organizations, assist in contributing access to a more extensive pool of candidates and has reduced time in recruitment and selection process. In spite of the significant cost reduction, the quality and competency of candidates have not deteriorated. The use of online networking has allowed Human resource professionals to gather standardized information of all candidates consequently ensuring fair to everyone.

It was found that a likely challenge would be the absence of equal prospect organization strategies that guide the utilization of online networking in the process of recruitment and selection. Additionally, the candidate's information privacy is the utmost priority of recruiters as it is ethically correct. They may share the information of candidates to the third party with their consent. It was examined that organizations are probably taking advantage of the utilization of online networking for the recruitment of Millennial (Generation Y) as it targets tech-savvy candidates. So far LinkedIn is the most favored social networking website for recruitment and selection. However, its acceptance in the organization is still less.

Lastly, it was also observed that majority of respondents were agreed that social media plays an essential role in the recruitment of Millennial (Generation Y) in most of the organizations and Human Resource Managers have access to an extensive pool of competent candidates from social networking sites, people are getting more job opportunities from both 
DOI: 10.14807/ijmp.v11i7.1130

social networking sites such as LinkedIn and Facebook as these sites are widely used. Companies clearly defined the job objectives, requirements and applicant specification in the recruitment and selection process, it was also discovered that online networking sites provide competent applicants and does timely recruitment and selection. In this way, the right candidate selected for the right job.

\section{LIMITATIONS}

The limitations of the study are as follows:

a) The study is based upon on different organizations of Pakistan only.

b) The Statistical Package of social science (SPSS) is applied as a research tool to assess the data, whereas the data can be used to extract more diversified insides by utilization of other research techniques.

c) The data is collected in a particular snapshot of time that is approximately 2 months making it cross-sectional research.

\section{Recommendations for future researchers:}

1) The study is conducted in the city of Pakistan only, whereas the dimension of the other country's organizations is ignored in the study. This would help in making a comparison of the effect social media sites on the recruitment and selection process in the different organizations of different countries.

2) This research comprised of the perceived costs, perceived benefits, perceived risk and perceived opportunities related to the utilization of social media recruitment campaign of Millennial (Generation Y). Comparable researches should be attempted but concentrate should be on the different Generations

\section{REFERENCES}

ARCHANA, L.; NIVYA, V. G.; THANKAM, S. M. (2014) Recruitment through social media area: Human Resource. Journal of Business and Management, v. 1, p. 37-41.

ARMSTRONG, M. (2010) Armstrong's essential human resource management practice: A guide to people management. Kogan Page Publishers.

BOLOTAEVA, V.; CATA, T. (2010) Marketing opportunities with social networks. Journal of Internet Social Networking and Virtual Communities, p. 1-8.

BONETT, D. G.; WRIGHT, T. A. (2015) Cronbach's alpha reliability: Interval estimation, hypothesis testing, and sample size planning. Journal of Organizational Behavior, v. 36, n. 1, p. 3-15. 
BOSWORTH, D. L.; KIK, G.; CONSTABLE, S. (2012) UK Commission's employer skills survey 2011: Northern Ireland results.

BOWLING, A. (2005) Mode of questionnaire administration can have serious effects on data quality. Journal of Public Health, v. 27, n. 3, p. 281-291.

BROWN, V. R.; VAUGHN, E. D. (2011) The writing on the (Facebook) wall: The use of social networking sites in hiring decisions. Journal of Business and Psychology, v. 26, n. 2, p. 219.

BRYMAN, A. (2006) Integrating quantitative and qualitative research: How is it done? Qualitative Research, v. 6, n. 1, p. 97-113.

CAPPELLI, P. (2001) On-line recruiting. Harvard Business Review, v. 79, n. 3, p. 139-146.

CLARK, L. A.; ROBERTS, S. J. (2010) Employer's use of social networking sites: A socially irresponsible practice. Journal of Business Ethics, v. 95, n. 4, p. 507-525.

CLEMENTS, A. (2012) Social media and recruitment: Time for a coherent HR strategy? HR Magazine, v. 16.

COMPTON, R. L. (2009) Effective recruitment and selection practices. CCH Australia Limited.

DAVISON, H. K.; MARAIST, C.; BING, M. N. (2011) Friend or foe? The promise and pitfalls of using social networking sites for HR decisions. Journal of Business and Psychology, v. 26, n. 2, p. 153-159.

DAVISON, P. (2012) The language of internet memes. The Social Media Reader, p. 120134.

DE ALWIS, A. C. (2010) The impact of electronic human resource management on the role of human resource managers. E+ M Ekonomie a Management, v. 4, p. 47.

DEKAY, S. (2009) Are business-oriented social networking web sites useful resources for locating passive jobseekers? Results of a recent study. Business Communication Quarterly, v. 72, n. 1, p. 101-105.

EDOSOMWAN, S.; PRAKASAN, S. K.; KOUAME, D.; WATSON, J.; SEYMOUR, T. (2011) The history of social media and its impact on business. Journal of Applied Management and Entrepreneurship, v. 16, n. 3, p. 79.

ELLISON, N. B. (2007) Social network sites: Definition, history, and scholarship. Journal of Computer-Mediated Communication, v. 13, n. 1, p. 210-230.

FREER, T. (2011) Social media gaming-a recipe for employer brand success. Strategic HR Review, v. 11, n. 1, p. 13-17.

HUNT, K. G. (2010) Finders keepers: Social media strategies help find top talent. Journal of Property Management, v. 75, n. 6, p. 36-41.

JOOS, J. G. (2008) Social media: New frontiers in hiring and recruiting. Employment Relations Today, v. 35, n. 1, p. 51-59.

KAPLAN, A. M.; HAENLEIN, M. (2010) Users of the world, unite! The challenges and opportunities of Social Media. Business Horizons, v. 53, n. 1, p. 59-68.

MILANO, R.; BAGGIO, R.; PIATTELLI, R. (2011) The effects of online social media on tourism websites. ENTER, p. 471-483.

MURIITHI, J. G.; GACHUNGA, H.; MBURUGU, C. K. (2014) Effects of Human resource 
DOI: 10.14807/ijmp.v11i7.1130

information systems on Human resource management practices and firm performance in listed commercial banks at Nairobi securities exchange. European Journal of Business and Management, v. 6, n. 29, p. 47-55.

NDAMBIRI, C. W. (2017) An Analysis of Social Media Use in the Recruitment and Selection of Young Professionals: A Case of Commercial Banks in Kenya. United States International University-Africa.

RAI, S. (2012) Engaging young employees (Gen Y) in a social media dominated worldReview and Retrospection. Procedia-Social and Behavioral Sciences, v. 37, p. 257-266.

SANSONI, J. E. (2011) Questionnaire design and systematic literature reviews.

SCOTT, P. R.; JACKA, J. M. (2011) Auditing social media: A governance and risk guide. John Wiley \& Sons.

SEARLE, R. H. (2006) New technology: The potential impact of surveillance techniques in recruitment practices. Personnel Review, v. 35, n. 3, p. 336-351.

SMITH, A. D.; RUPP, W. T. (2004) Managerial challenges of e-recruiting: Extending the life cycle of new economy employees. Online Information Review, v. 28, n. 1, p. 61-74.

SUBHANI, M. I.; JOSEPH, S.; OSMAN, A.; HASAN, S. A. (2012) Contribution of Linkedin on Recruitment and Selection. South Asian Journal of Management Sciences (SAJMS, p. Iqra University, v. 6, n. 2, p. 23-34.

WOLF, M. V.; SIMS, J.; YANG, H. (2014a) Social media utilization in human resource management. Web Based Communities and Social Media 2014 Conference (WBC 2014); 8th Multi Conference on Computer Science and Information Systems, Portugal, Lisbon.

WRIGHT, N. (2011) The impact of social media on recruitment. Retrieved September, 5, 2013. 